\title{
EXPERIMENTAL INVESTIGATIONS ON MECHANICAL AND WEAR BEHAVIOR OF HYBRID ALUMINIUM ALLOY
}

\author{
Bharath. $\mathrm{T}^{\mathbf{1}}$,Rajesh. A. $\mathbf{M}^{\mathbf{2}}$,Mohammed Kaleemulla ${ }^{3}$, K.Rangasravantha ${ }^{4}$ \\ ${ }^{1}$ Student, Department ofaMechanical Engineering, S.J.M Institute of Technology, Chitradurga, Karnataka, INDIA \\ stswamy62@gmail.com,rangasravanth@gmail.com, \\ ${ }^{2}$ Assistant professor, Department ofaMechanical Engineering, S.J.M Institute of Technology, Chitradurga, Karnataka, \\ INDIA. \\ rajesh.am82@gmail.com,rajesh.am82@rediffmail.com. \\ ${ }^{3}$ Assistant professor, Department ofaMechanical Engineering, UBDT college, Davanagare, Karnataka, INDIA.
}

\begin{abstract}
:
Automotive sector essentially needs aluminium because of its better mechanical properties, good corrosion resistance, wear resistance and having light weight compared to other metals. The present work is focussed to develop a hybrid metal matrix composite is to add the desired attributes, to study the change in behaviour of hybrid aluminium by varying percentage(10\%) of Silicon carbide and Aluminium oxide composites and compare the test results with pure aluminium-7075. The Micro-Hardness test, wear test has performed on these samples by using pin on disc apparatus wear test will be carried on all the samples at various speeds of 200,400 \& $600 \mathrm{rpm}$, varying load of $2 \mathrm{~kg}, 4 \mathrm{~kg} \& 6 \mathrm{~kg}$. Which are produced by stir casting. The stir casting process has been used for the development of the composite system. The matrix material was melted in electric furnace and the pre-heat treated reinforcement at $810^{\circ} \mathrm{C}$ in the desired volume fraction have been added followed by constant stirring the melt. The temperature of the melt held at $720^{\circ} \mathrm{C}$. The pouring temperature was recorded which has relation to quality of the casting. Therefore Reinforcement of aluminium oxide and silicon carbide to the hybrid aluminium increases its strength and properties compared to pure aluminium 7075 metal. The wear resistance increases with the increase in the reinforcement weight fraction. The addition of Silicon Carbide apart from improving the wear rate reduces the noise and vibration at higher speed and load condition. The overall tribological property improves due to addition of the two reinforcements.
\end{abstract}

Keywords: Composites, Sic, Alumina, Wear, Hardness

\section{INTRODUCTION}

The Purpose of manufacturing aluminium metal matrix composite is to combine the important properties of metals and ceramics. The addition of high strength particles to a metal matrix increases its strength and properties that that is which is intermediate between the matrix alloy and reinforcement particles. After oxygen and silicon aluminium is the most abundantly available metal in the earth's crust. There is a high demand for aluminium products in the consumer field due to their high strength, lightweight, durability and higher corrosion resistance. Aluminium is the most widely used metal after iron in today's manufacturing field.

Aluminium metal matrix composites is the most promising and widely used materials because of their good mechanical properties, less investments and lower production and maintenance cost and can be able to form from conventional metal processing technique. The aim involved in designing Aluminium matrix composite (AMC) is to combine the desirable attributes of metal and ceramics to aluminium matrix metal. However, there are some restrictions in producing superior quality metal matrix composites. The major problem is difficult to achieve excellent bond between matrix metal and reinforcement paricles. We can overcome the above problems by adopting stir casting technique for making metal matrix composites.

Particle reinforced aluminium matrix composite possesses the significantly enhanced properties including high strength, high stiffness and damping capacity compared with the unreinforced alloy matrix. Sic particle and Alumina reinforced aluminium composites have higher demand in market than other kinds of MMC's due to their high mechanical properties, high performance, wear resistance, low thermal expansion coefficient and high thermal conductivity. Therefore they are more competitive on MMC market and find wider application in industries ${ }^{[2]}$. The aluminium alloy Al7075 has been selected as the matrix material is more compatible with the reinforcement and has good mechanical property and castability at the alloy level itself. The reinforcement selected as alumina $\left(\mathrm{Al}_{2} \mathrm{O}_{3}\right)$ in the form of particle size 100-200mesh.. It is more stable with aluminium and withstands high temperature. It is an oxide ceramic having low affinity for the oxygen to form oxides. The particulate form of the reinforcement has better distribution in the matrix to provide isotropic property for the composite. The Silicon carbide has been selected as the next ceramic which is a carbide type of ceramic. The SiC has good lubricating effect along with it reduces the noise and vibration during the relative motion ${ }^{[3]}$. 
When Aluminium 7075 alloy matrix metal reinforced with combined $\mathrm{SiC}$ and $\mathrm{Al}_{2} \mathrm{O}_{3}$ particles exhibites improved mechanical properties compared to the composites reinforced with either sic or alumina alone. Hardness of the composite increase because of increase in ceramic phase due to addition of sic particulates. Oxidation resistance of matrix material was significantly improved using sic particulate with a addition of $\mathrm{Al}_{2} \mathrm{O}_{3}$.

The composite has been fabricated by stir casting technique. The stir casting technique is an suitable and economical processing method for producing AMC's as it is relatively inexpensive and offers a wide selection of materials and processing conditions. Stir casting technique is suitable for mass production of complex profiled composite components without damaging the reinforcement particles.

Aluminium7075 is an aluminium alloy in which zinc is a primary alloying element. The composition and properties of aluminium7075 is shown below;

Table 1: Composition of Aluminium 7075.

\begin{tabular}{|l|l|l|l|l|l|l|l|l|l|}
\hline $\begin{array}{l}\text { ELEME } \\
\text { NT }\end{array}$ & $\mathrm{Cr}$ & $\mathrm{Ti}$ & $\begin{array}{l}\mathrm{M} \\
\mathrm{n}\end{array}$ & $\mathrm{Si}$ & $\begin{array}{l}\mathrm{F} \\
\mathrm{e}\end{array}$ & $\begin{array}{l}\mathrm{C} \\
\mathrm{u}\end{array}$ & $\begin{array}{l}\mathrm{M} \\
\mathrm{g}\end{array}$ & $\begin{array}{l}\mathrm{Z} \\
\mathrm{n}\end{array}$ & $\mathrm{Al}$ \\
\hline $\begin{array}{l}\text { PERCE } \\
\text { NT }\end{array}$ & $\begin{array}{l}0.1 \\
(\%)\end{array}$ & 0. & 0. & 0. & 0. & 1. & 2. & 5. & 88. \\
& 2 & 3 & 4 & 5 & 6 & 5 & 5 & 85 \\
\hline
\end{tabular}

\section{EXPERIMENTAL PROCEDURE}

The Al7075 matrix metal which is in the form of ingot is cutted randomly into small pieces. The pieces are cleaned to remove dust and oil. For ascast the measured quantity of Al7075 is melted in a induction furnace with the help of graphite crucible upto $720^{\circ} \mathrm{C}$ all the necessary measures are taken and the molten metal is stirred manually for about 5minutes. Then the molten metal is poured to preheated graphite mould, then it is allowed to cool. The castings are taken out from the mould. When adding reinforcements to the matrix metal, according to volume ratio the silicon carbide and aluminium oxide reinforcements of $10 \%$ with respect to the weight of $\mathrm{Al} 7075$ is preheated upto $850^{\circ} \mathrm{C}$ in a muffle furnace. On the other hand the Al7075 is heated in a induction furnace, when the metal is melted a pinch of degassifier is added to remove the waste gases if present. The slag is removed from the molten metal. The reinforcements which are preheated are added to the molten metal and stirred the mixture constantly for about5-10min. A pinch of cover flux is added. Again stirred and allowed for about $5 \mathrm{~min}$, then the molten metal is poured into the preheated graphite mould. After some time the castings are taken out from the mould. The castings are machined in a conventional lathe as per ASTM standards for making wear and hardness test.

The wear test is conducted on the specimens having dimensions of $10 \mathrm{~mm}$ diameter and $35 \mathrm{~mm}$ length for ascast and $10 \%$ reinforcements. The wear test is conducted by using pin-on-disc apparatus. For 200rpm speed of disc $2 \mathrm{~kg}$ load is applied for 5minutes and the same is repeated by applying $4 \mathrm{~kg}, 6 \mathrm{~kg}$ load. Then the same is followed for 400rpm and 600rpm disc speed. The weight loss technique is followed to measure the amount of wear of specimen.

The Micro Hardness test is conducted on the specimens by using Vicker's Hardness tester. The dimension of the specimens for hardness test is 25 mmdiameter and 1 " length. A $200 \mathrm{gm}$ of load is applied for a period of 40seconds on the specimen and at a total magnification of 400x. The Vicker's hardness number for ascast and $10 \%$ reinforcement is obtained.

\section{EXPERIMENTAL RESULTS}

\section{A) Micro Hardness test results}

In this test a diamond indentor is used to apply load. 200gm of load is applied on the specimen without any jerk for about 40 seconds. By using vicker's hardness tester's microscope we measure the dimensions of the indentation. The below Table 2 shows the vicker's hardness number for ascast and $10 \%$ reinforcement of sic and alumina. Figure 1 shows the graph plotted for vicker's hardness number again the reinforcements of specimens.

Table 2

\begin{tabular}{|l|l|l|}
\hline $\begin{array}{l}\text { Sl. } \\
\text { No }\end{array}$ & $\begin{array}{l}\text { \% Composition of } \\
\text { Reinforcement }\end{array}$ & Hardness(VHN) \\
\hline 1 & Pure $\mathrm{Al} 7075$ & 107 \\
\hline 2 & $\begin{array}{l}\mathrm{Al} 7075+10 \% \mathrm{SiC}+ \\
10 \% \mathrm{Al}_{2} \mathrm{O}_{3}\end{array}$ & 119 \\
\hline
\end{tabular}

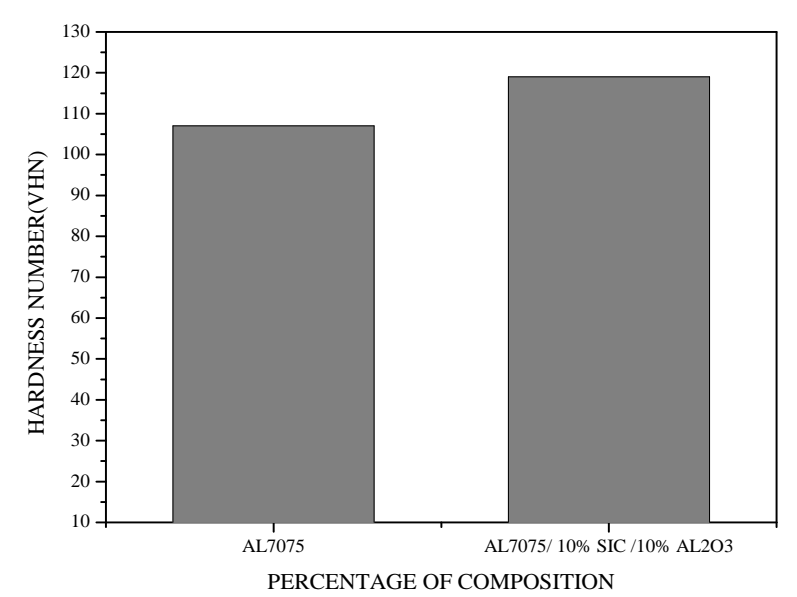

Figure 1

\section{B) Wear test results}

The wear tests were conducted on the specimens of ascast and $10 \%$ reinforcement. The results are plotted and it shows that the mechanical properties of the reinforced material is increased compared to material without reinforcement. The below figure 2, 3, 4 shows the graph plotted for load in $\mathrm{N}$ $\mathrm{v} / \mathrm{s}$ weight loss in gms for 200, 400, 600rpm respectively. Figure 5, 6, 7 shows the graph of load v/s volumetric wear rate for 200, 400 and 600rpm of disc speed. 


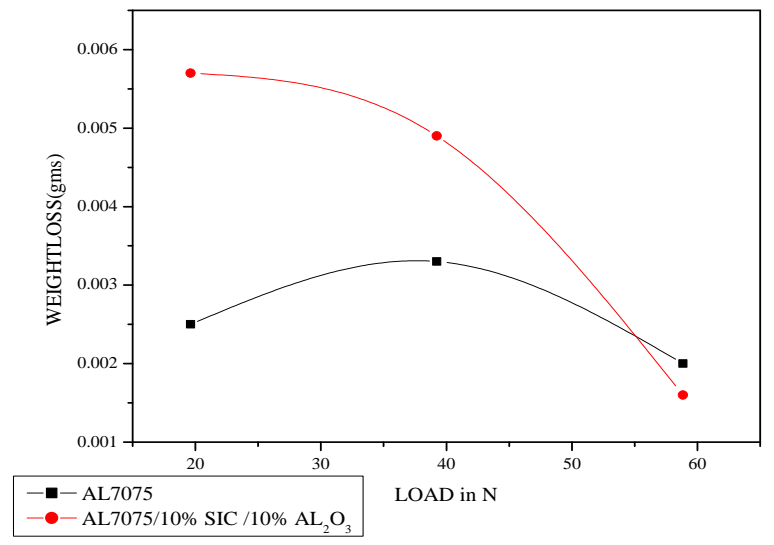

Figure 2

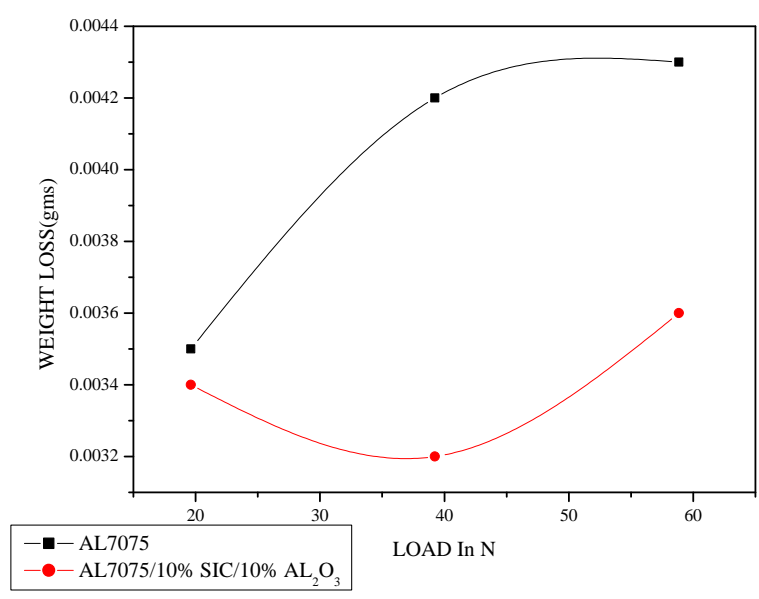

Figure 3

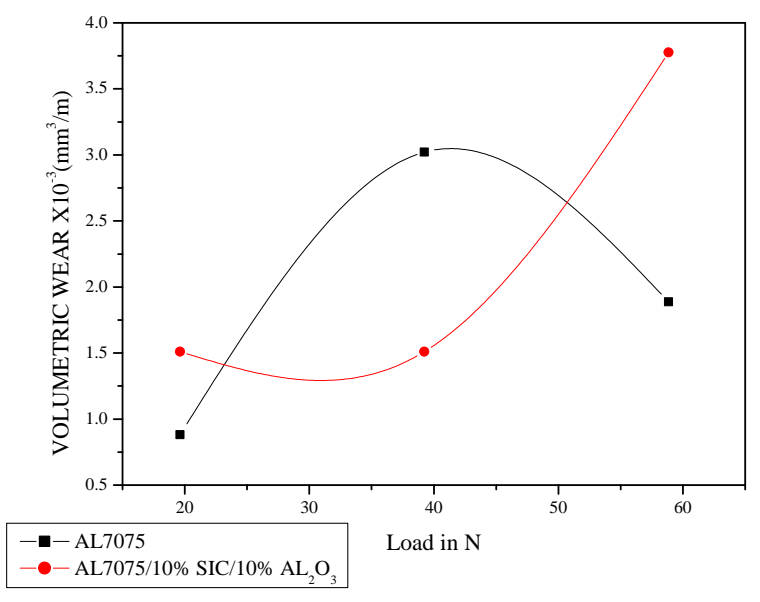

Figure 4 Figure 5

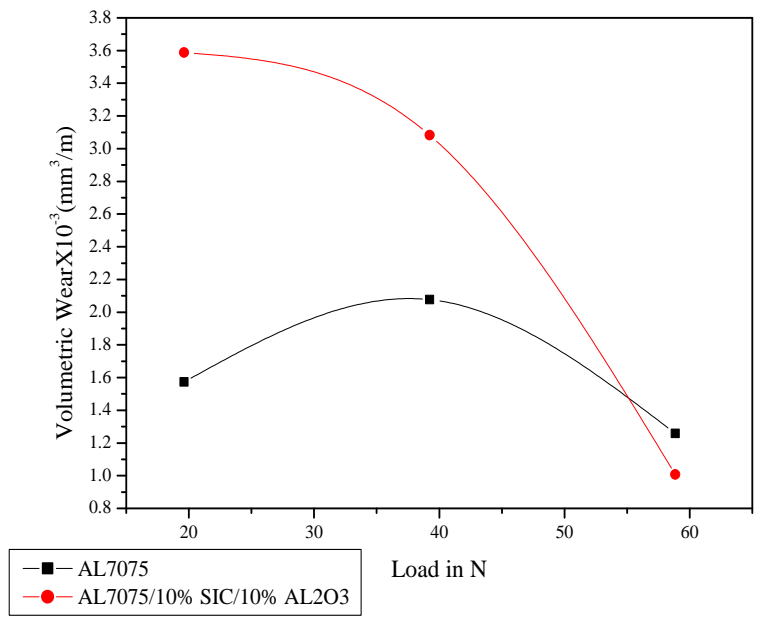

Figure 6

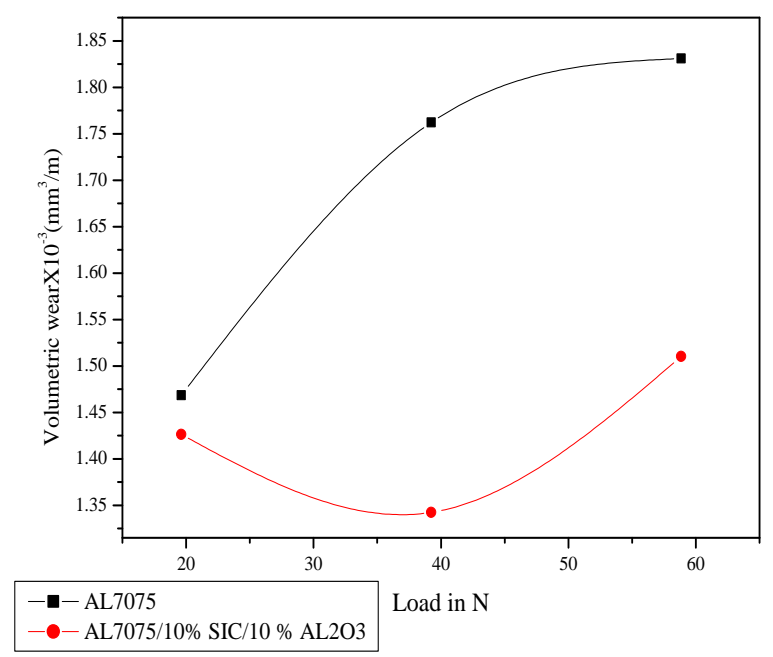

Figure 7

\section{CONCLUSION}

The mechanical properties of the ascast and composites were tested and compared. The results reveals that the percentage of reinforcement of silicon carbide and aluminium oxide to aluminium metal matrix influence the mechanical properties of $\mathrm{Al} 7075-\mathrm{Sic}-\mathrm{Al}_{2} \mathrm{O}_{3}$ hybrid metal matrix composite.

Aluminium 7075 with $10 \%$ of $\mathrm{SiC}$ and $10 \%$ of $\mathrm{Al}_{2} \mathrm{O}_{3}$ has a maximum hardness and increased wear resistance compared to Al7075 without reinforcement.

By adding more than $20 \%$ of reinforcement to aluminium matrix alloy, the mechanical properties of metal matrix composites comes below the normal level because of uneven distribution of particles of reinforcement in the matrix alloy.

The results revealed that the addition of silicon carbide and alumina particles to aluminium matrix improves. 


\section{REFERENCES}

[1]. Daljeet Singh, Harmanjit Singh, Som Kumar And Gurvishal Singh, “ An Experimental Investigation On Mechanical Behavior Of Aluminum By Adding Sic And Alumina". International Journal On Emerging Technologies.

[2]. B. Sundar, B. Rajeswari, K.S. Amrithagadeswaran, "Studies Of Mechanical Properties On Aluminium Hybrid Metal Matrix Composite". International Journal On Emerging Researches In Engineering Science And Technology.

[3]. Raghavendra N And V S Ramamurthy, "Tribological Characterization of $\mathrm{Al} 7075 / \mathrm{Al}_{2} \mathrm{O}_{3} / \mathrm{Sic}$ Reinforced Hybrid Particulate Metal Matrix Composite Developed By Stir Casting Process". International Journal On Recent Advances In Mechanical Engineering.

[4]. Rajendra. S. K, Ramesha. C. M, "A Survey Of Al7075 Aluminium Metal Matrix Composites". International Journal Of Science And Research.

[5]. S. Ezhil Vannan, S. Paul Vizhian, "Microstructure And Mechanical Properties Of As Cast Aluminium Alloy 7075/Basalt Dispersed Metal Matrix Composites". Journal Of Minerals And Materials Characterization And Engineering.

[6]. G. B. Veeresh Kumar, C. S. P. Rao, N. Selvaraj, M. S. Bhagyashekar, "Studies On Al6061-Sic And Al7075$\mathrm{Al}_{2} \mathrm{O}_{3}$ Metal Matrix Composites". Journal Of Minerals And Materials Characterization And Engineering.

[7]. R. Keshavamurthy, Sadananda Mageri, "Microstructure And Mechanical Properties Of Al7075-Tib 2 In Si-Tu Composite". Research Journal Of Material Science 